\title{
Reduced uptake of mass treatment for schistosomiasis control in absence of food: beyond a randomized trial
}

\author{
Simon Muhumuza ${ }^{1 *}$, Annette Olsen ${ }^{2}$, Anne Katahoire ${ }^{1}$ and Fred Nuwaha ${ }^{3}$
}

\begin{abstract}
Background: Sustaining high uptake of praziquantel is key for long-term control of schistosomiasis. During mass treatment in 2013, we randomized 12 primary schools into two groups; one group received education messages for schistosomiasis prevention for two months prior to mass treatment, while the other, in addition to the education messages, received a pre-treatment snack shortly before mass treatment. The uptake of praziquantel in the snack schools was $94 \%$ compared to $79 \%$ in the non-snack schools. During mass treatment in 2014, no snack was provided. We compared the uptake of praziquantel in 2014 to that in 2013 and attempt to explain the reasons for the observed differences.
\end{abstract}

Methods: Serial cross sectional surveys were conducted among a random sample of children from the 12 primary schools, 1 month after mass treatment in 2013 and 2014 to measure uptake of praziquantel, reported side effects attributable to praziquantel and prevalence and intensity of schistosomiasis infection. Differences in the demographic and descriptive variables between the 2013 and 2014 samples were compared using chi squared tests for categorical variables and student's $t$-test for geometric mean intensity of $S$. mansoni infection.

Results: Uptake of praziquantel reduced from 93.9 to $78.0 \%(p=0.002)$ in the snack schools but was unchanged in the non-schools 78.7 and $70.4 \%(p=0.176)$. The occurence of side-effects attributable to praziquantel increased from 34.4 to $61.2 \%(p=0.001)$ in the snack schools but was unchanged in the non-snack schools; 46.9 and $53.2 \%$ $(p=0.443)$. Although the prevalence of $S$. mansoni infection increased in both the snack and non-snack schools, the differences did not reach statistical significance; 1.3 and $7.5 \%(p=0.051)$ and 14.1 and $22.0 \%(p=0.141)$, respectively. Similarly, the difference in the geometric mean intensity of $S$. mansoni infection in both the snack and non-snack schools was not statistically significant; 38.3 eggs per gram of stool (epg) and $145.7 \mathrm{epg}(p=0.197)$ and $78.4 \mathrm{epg}$ and 322.5 epg $(p=0.120)$, respectively.

Conclusion: Our results show that in absence of food, uptake of praziquantel reduced and the side-effects of the drug increased. However, the reduced uptake did not affect the prevalence and intensity of schistosomiasis among school children. Rescinding of the provision of the snack is what probably caused the reduction in uptake of treatment in the subsequent mass treatment cycle.

Keywords: Uptake of praziquantel, Feeding program, School children, Uganda

\footnotetext{
* Correspondence: simonmhmz@yahoo.com

${ }^{1}$ School of Medicine, Child Health and Development Center, Makerere

University, Kampala, Uganda

Full list of author information is available at the end of the article
} 


\section{Background}

The goal of the Ugandan national schistosomiasis control program is morbidity control through regular mass treatment in endemic areas [1]. Annual school-based mass treatment with praziquantel is the cornerstone for schistosomiasis control among school-aged children. The school approach is based on the premises that it is cost-effective to deliver interventions through the school system because schools are widely distributed and that school teachers can assist to administer the drugs to the children [2-5]. The drawbacks of this strategy have been documented in many parts of the country. The reliance on volunteer teachers to distribute treatment, the fear of side-effects of praziquantel, low school attendance rates and the social, economic and political context in which mass treatment is rolled out profoundly affect the uptake of drugs among the targeted population [6-9]. In some locations, uptake of treatment has been found to be low [8-11]. The target is to treat at least $75 \%$ of school-age children at risk of morbidity [12]. In a particular study conducted in Jinja district, less than $30 \%$ of the school children took praziquantel during mass treatment in 2011. The fear of treatment, inadequate health education and lack of teacher support were some of the factors thought to influence the uptake [11]. In an effort to increase the uptake of treatment in 2012, the national control program motivated the teachers to distribute treatment through provision of incentives and intensified supervision with little success [13].

Praziquantel should be concurrently administered with food to mitigate the side effects of the drug and increase its uptake [14-16]. Studies assessing the use of food incentives have shown improved participation of children in health programs for treatment of schistosomiasis, HIV/AIDS and other diseases [16-19]. Furthermore, the use of food is associated with improved treatment outcomes and education benefits among school children $[17,20,21]$. In Uganda, the school feeding policy requires that parents take responsibility for feeding their children while at school [22]. However, due to the prevailing poverty in many parts of the country, most parents cannot afford to meet the cost of a daily meal for their children while at school [23]. In areas where annual treatment with praziquantel for schistosomiasis control is provided, most children take the treatment on an empty stomach and experience side effects [24, 25] and as such, reject the drug during the subsequent mass treatment programs $[9,26]$.

Strategies for improving uptake, such as provision of food to mitigate the side effects of praziquantel and motivate children to take treatment are required. Our study conducted in 2013 demonstrated the effectiveness of a pre-treatment snack on the uptake of praziquantel among school children [27]. This study compares the
2013 uptake with the 2014 uptake when no snack was provided. In addition, the reported side effects attributable to praziquantel and prevalence and intensity of schistosomiasis infection are compared.

\section{Methods}

\section{Ethical considerations}

Ethical permit to conduct the study was obtained from the School of Medicine Research and Ethics Committee, Makerere University and the Uganda National Council for Science and Technology. Clearance to conduct the study in the schools was obtained from the school management. Written informed consent from the parents and guardians of the children was obtained through half-day meetings held at the respective schools. Assent to participate in the study was obtained from all the children. Children identified with schistosomiasis and/or STH were treated with praziquantel and/or albendazole.

\section{Study design}

Serial cross sectional surveys were carried out 1 month after mass treatment in 2013 and 2014. Both surveys employed similar quantitative methods of data collection.

\section{Study setting}

The surveys were carried out in 12 primary schools of Walukuba division, Jinja district of south eastern Uganda, where intestinal schistosomiasis is highly endemic. This setting has been described in our earlier studies [11, 26, 27]. Briefly, annual school-based mass treatment is implemented as the main strategy for schistosomiasis control in the division. Treatment to the school children is distributed and registered by trained teachers who are supervised by sub-county health assistants and inspector of schools. However, uptake of praziquantel among school children in the area was low. Prior to the 2013 mass treatment, the 12 primary schools in the division were randomized into two groups; one received education messages for schistosomiasis prevention for two months prior to mass treatment, while the other, in addition to the education messages, received a snack before mass treatment. Each child in the snack schools received $500 \mathrm{ml}$ of mango juice and a doughnut shortly before swallowing praziquantel during mass treatment. The education messages focused on the prevention aspects of schistosomiasis infection including taking preventive treatment (praziquantel) with food in order to avoid the side-effects of the drugs. Both the snack and the education messages were delivered by the teachers. These interventions were supported by the Danish Ministry of Foreign Affairs. The uptake of praziquantel in the snack schools (93.9\%) was considerably higher than in the nonsnack schools $(78.7 \%)$. The occurrence of the side effects 
as well as the prevalence and geometric mean intensity of $S$. mansoni infection were considerably lower in the snack schools than in the non-snack schools [27]. Prior to the 2014 mass treatment, information about mass drug distribution was communicated through radio talk shows and spot messages. However, there was no snack provided to the children prior to treatment.

\section{Sample size}

The uptake of praziquantel used to estimate the sample size for this study was derived from our previous study. It was assumed that uptake of treatment would decrease from $94 \%$ in 2013 [27] to $75 \%$ in 2014. At a $90 \%$ power and a $95 \% \mathrm{CI}$, the sample size required to test this difference was 85 in the snack schools and 85 in the non-snack schools according to STATA 12.0 (TX, USA). Because of the cluster design, a design effect of 6.3 from the previous study was applied to obtain a minimum sample size of 536 in the snack schools and 536 in the non-snack schools. In this study, 1,142 children were randomly selected from the 12 primary schools to participate in the 2014 study.

\section{Sampling and data collection}

Similar sampling and data collection methods as those used in the previous study were employed [27]. Children in the two groups were randomly selected from grade (year) 4-6. A proportionate number of children selected from each school and grade was determined by probability proportional to size of the school and grade population. Systematic sampling was used to select the children from each grade to participate in the face to face interviews using a structured questionnaire and undergo a stool examination for $S$. mansoni infection using the modified Kato-Katz thick smear technique with a $41.7 \mathrm{mg}$ template [28].

\section{Measures}

Measures included self-reported uptake of praziquantel, occurrence of side-effects and prevalence and intensity of $S$. mansoni infection in the two groups. In addition, the socio-demographic characteristics of the children and their knowledge of schistosomiasis prevention were assessed. Uptake of praziquantel was measured on a score scale of 1-4. Children were asked whether they received treatment, and if they did, they were further asked the colour and the taste of the tablets, and whether they swallowed the drugs. For each positive response, a score of one was awarded. Children who reported to have received the drug, mentioned the true colour and taste of praziquantel and reported to have swallowed the tablets scored an aggregate of four and this was considered as true uptake of praziquantel. In addition, children who reported to have swallowed treatment were asked if they developed any side effects after swallowing the drug. Knowledge of schistosomiasis prevention was measured on a score scale of $1-3$. Children were asked the different ways through which the infection can be transmitted and prevented. For each of the correct responses, a score of one was awarded. Children who mentioned at least one correct method of transmission and two correct methods of prevention scored an aggregate of three and were regarded as having correct knowledge of schistosomiasis prevention.

\section{Laboratory diagnosis of S. mansoni infection}

In order to determine the prevalence and intensity of $S$. mansoni infection, we examined one early morning stool specimen from each child on two consecutive days using the modified Kato-Katz faecal thick smear technique [28] with a $41.7 \mathrm{mg}$ template. The Kato-Katz method was adopted because it is simple, low cost and uses an already established system to stratify infection intensities into different classes based on cut offs of egg-counts [29, 30]. Two slides per stool specimen were prepared and examined by two independent laboratory technicians. A discrepancy of more than $5 \%$ in egg counts was validated by a third laboratory technician who read the results for confirmation and the counts harmonized. The egg counts were found to be over dispersed and thus were logarithmically transformed and intensities reported as geometric mean intensity (GMI) of eggs per gram of stool (epg) among positive cases only.

\section{Data management and statistical analysis}

Data entry and validation was performed in Microsoft Access 2007 and exported to STATA 12.0 (TX, USA) for analysis. Analysis was done at both the cluster and individual levels. Mean and standard deviation (S.D) were used to describe continuous data. Differences in the demographic and descriptive variables between the 2013 and 2014 children samples were compared using chi squared tests for categorical variables. Student's $t$-test was used to compare mean intensity of S. mansoni infection. Multivariable regression was done to identify the independent predictors of uptake of praziquantel. Clustering was adjusted for by dividing test statistics based on chi squared tests and the $t$ - test with the design effect and the square root of the design effect [31, 32], respectively. The intracluster correlation coefficient (ICC) was 0.06 and the design effect was 6.3.

\section{Quality control}

Data were collected by experienced research assistants who are fluent in the local language of Lusoga. Similar data collection tools as those used in 2013 were employed [27]. To ensure completeness and accuracy, data were checked before leaving the field and as such, 
no data were missing. The first author closely supervised the research assistants during data collection.

\section{Results}

\section{Demographic characteristics}

Overall, a total of 2,426 children in 12 primary schools were assessed one month after mass treatment in 2013 and 2014: 1,284 children in 2013 and another 1,142 in 2014. Of the 1,284 children assessed in 2013, 595 (46.3\%) were from the snack schools and 689 (53.7\%) were from the non-snack schools. Of the 1,142 children assessed in 2014, 496 (43.4\%) and 646 (56.6 \%) were from the snack and non-snack schools, respectively. The mean age of children in the snack schools was 11.3 years (standard deviation [SD] 1.7) in 2013 and 11.6 years (SD 1.5) in 2014 while that in the non-snack schools was 11.7 years (SD 1.6) in 2013 and 12.2 years (SD 1.8) in 2014. Children in the snack and non-snack schools in the 2013 and 2014 samples were comparable in terms of age group, sex and distance from area of residence to the lake $(p>0.05)$ (Table 1$)$.

\section{Self-reported uptake of praziquantel and occurrence of side-effects}

A significant decrease in uptake of praziquantel from $93.9 \%$ (95 \% CI 91.7-95.7 \%) in 2013 to $78.0 \%$ (95 \% CI $74.1-81.6 \%)(p=0.002)$ in 2014 was observed in the snack schools. However, uptake in the non-snack schools was unchanged; $78.7 \%$ (95 \% CI 75.4-81.7 \%) in 2013 and $70.4 \%$ (95 \% CI 66.7-73.9\%) $(p=0.176)$ in 2014 (Table 2). The 2014 uptake in the snack and nonsnack was comparable; $78.0 \%$ (95 \% CI 74.1-81.6\%) and $70.4 \%$ (95 \% CI 66.7-73.9 \%) ( $p=0.250$ ), respectively.

A considerable increase in the occurrence of side-effects attributable to praziquantel was observed in the snack schools in 2013; from 34.4 \% (95 \% CI 31.5-39.8\%) in 2013 to $61.2 \%$ (95 \% CI 56.2-66.1\%) $(p=0.001)$ in 2014.
However, the occurrence of side-effects was unchanged in the non-schools; $46.9 \%$ (95 \% CI 42.2-50.7 \%) in 2013 and $53.2 \%$ (95 \% CI 48.5-57.9\%) $(p=0.443)$ in 2014. A significant decrease in the proportion of children who reported to have eaten something prior to mass treatment was noted in both the snack and non-snack schools from $92.8 \%$ (95 \% CI 90.4-98.4) to 54.4 \% (95 \% CI 48.8-58.9\%) $(p<0.001)$ in 2014 and from $49.8 \%$ (95 \% CI 45.5-54.1\%) to $32.5 \%$ (95\% CI $28.2-37.0 \%)(p<0.001)$ in 2013 , respectively. The frequency of side-effects in the snack and non-snack schools in 2014 was comparable; $61.2 \%$ (95 \% CI 56.2-66.1 \%) and $53.2 \%$ (95 \% CI 48.5-57.9\%) $(p=0.349)$, respectively. The proportion of children who reported to have eaten something prior to mass treatment in 2014 was $54.4 \%$ (95 \% CI 48.8-58.9 \%) in the snack schools compared to $32.5 \%$ (95 \% CI 28.2$37.0 \%)(p=0.011)$ in the non-snack schools.

\section{Prevalence and mean intensity of S. mansoni infection}

Prevalence of $S$. mansoni infection in the snack schools was unchanged;1.3\% (95\% CI 0.6-2.6\%) in 2013 and $7.5 \%$ (95 \% CI 5.3-10.1 \%) ( $p=0.051)$ in 2014. Similarly, the prevalence of S. mansoni infection in the non-snack schools was unchanged; $14.1 \%$ (95\% CI 11.6-16.9\%) in 2013 and $22.0 \%$ (95\% CI 18.8-25.4\%) $(p=0.141)$ in 2014. A statistically significant difference in the prevalence of $S$. mansoni infection was noted between the snack and non-snack schools in 2014; $22.0 \%$ (95\% CI $18.8-25.4 \%)$ and $7.5 \%$ (95 \% CI 5.3-10.1 \%) ( $p=0.008)$, respectively.

Although the mean intensity of S. mansoni infection increased in both the snack and non-snack schools, the differences did not reach statistical significance; 38.3 epg (95 \% CI 21.8-67.2) in 2013 and 145.7 epg (95\% CI 92.6-229.5) $(p=0.197)$ in 2014 and $78.4 \mathrm{epg}(95 \%$ CI 60.6-101.5) in 2013 and 322.5 epg (95 \% CI 258.1403.1) $(p=0.120)$ in 2014, respectively (Table 2$)$.

Table 1 Comparison of the children in the two groups of schools after the 2013 and 2014 mass treatment

\begin{tabular}{|c|c|c|c|c|c|c|c|c|}
\hline \multirow[t]{3}{*}{ Characteristic } & \multicolumn{4}{|c|}{ Non-snack schools } & \multicolumn{4}{|l|}{ Snack schools } \\
\hline & \multirow{2}{*}{$\begin{array}{l}2013 \\
n=(689)(\%)\end{array}$} & 2014 & \multirow[t]{2}{*}{$x^{2 a}$} & \multirow[t]{2}{*}{$p$-Value } & \multirow{2}{*}{$\begin{array}{l}2013 \\
n=(595)(\%)\end{array}$} & 2014 & \multirow[t]{2}{*}{$x^{2 a}$} & \multirow[t]{2}{*}{$p$-Value } \\
\hline & & $n=(646)(\%)$ & & & & $n=(496)(\%)$ & & \\
\hline \multicolumn{9}{|l|}{ Age group } \\
\hline $07-11$ years & $291(42.2)$ & 301 (46.6) & 0.379 & 0.538 & $310(52.1)$ & 241 (48.6) & 0.190 & 0.663 \\
\hline $12-16$ years & $398(57.8)$ & $345(53.4)$ & -——- & -—- - & $285(47.9)$ & $255(51.4)$ & -——- & 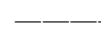 \\
\hline \multicolumn{9}{|l|}{ Sex } \\
\hline Female & $343(49.8)$ & $345(53.4)$ & 0.256 & 0.613 & $296(49.7)$ & $270(54.4)$ & 0.349 & 0.555 \\
\hline Male & $346(50.2)$ & 301 (46.6) & -——- & -——— & $299(50.3)$ & $226(45.6)$ & -二- & 一一一 \\
\hline \multicolumn{9}{|c|}{ Distance from area of residence to Lake Victoria } \\
\hline$\leq 5 \mathrm{~km}$ & $330(47.9)$ & $300(46.4)$ & 0.037 & 0.847 & $284(47.7)$ & $243(49.0)$ & 0.021 & 0.885 \\
\hline$>5 \mathrm{~km}$ & $359(52.1)$ & $346(53.6)$ & - - - - & - - - & $311(52.3)$ & $253(51.0)$ & -二- - & -—— \\
\hline
\end{tabular}

${ }^{\text {aAdjusted for cluster design effect }}$ 
Table 2 Characteristics of the snack and non-snack school after the 2013 and 2014 mass treatment

\begin{tabular}{|c|c|c|c|c|c|c|c|c|}
\hline \multirow[t]{3}{*}{ Characteristic } & \multicolumn{4}{|c|}{ Non-snack schools } & \multicolumn{4}{|l|}{ Snack schools } \\
\hline & 2013 & 2014 & Test Statistic ${ }^{a}$ & $p$-Value & \multirow{2}{*}{$\begin{array}{l}2013 \\
n=(595)(\%)\end{array}$} & \multirow{2}{*}{$\begin{array}{l}2014 \\
n=(496)(\%)\end{array}$} & \multirow[t]{2}{*}{ Test Statistic ${ }^{a}$} & \multirow[t]{2}{*}{$p$-Value } \\
\hline & $n=(689)(\%)$ & $n=(646)(\%)$ & & & & & & \\
\hline \multicolumn{9}{|c|}{ Knowledge of schistosomiasis prevention (\%) } \\
\hline Yes & $595(86.4)$ & $362(56.0)$ & $x^{2}=23.732$ & $<0.001$ & $500(84.0)$ & $308(62.1)$ & $x^{2}=10.574$ & 0.001 \\
\hline No & $94(13.6)$ & $284(44.0)$ & -—- & -——- & $95(16.0)$ & $188(37.9)$ & -—- & -—— \\
\hline \multicolumn{9}{|c|}{ Eaten food prior to mass treatment (\%) } \\
\hline Yes & $270(49.8)$ & $148(32.5)$ & $x^{2}=4.708$ & 0.030 & $519(92.8)$ & $211(54.4)$ & $x^{2}=30.103$ & $<0.001$ \\
\hline No & $272(50.2)$ & $307(67.5)$ & -—-- & -—— & $40(7.2)$ & $177(45.6)$ & -—- & -—- \\
\hline \multicolumn{9}{|c|}{ Self-reported uptake of praziquantel (\%) } \\
\hline Yes & $542(78.7)$ & $455(70.4)$ & $x^{2}=1.829$ & 0.176 & $559(93.9)$ & $387(78.0)$ & $x^{2}=9.231$ & 0.002 \\
\hline No & $147(21.3)$ & $191(29.6)$ & -—-— & -——— & $36(6.1)$ & $109(22.0)$ & -——- & -——- \\
\hline \multicolumn{9}{|c|}{ Side-effects attributable to praziquantel (\%) } \\
\hline Yes & $254(46.9)$ & $242(53.2)$ & $x^{2}=0.589$ & 0.443 & $192(34.3)$ & $240(61.2)$ & $x^{2}=10.486$ & 0.001 \\
\hline No & $288(53.1)$ & $213(46.8)$ & -—- & -——- & $367(65.7)$ & $152(38.8)$ & -—- & -—— \\
\hline \multicolumn{9}{|c|}{ Reported side-effects attributable to praziquantel (\%) } \\
\hline Abdominal pain & $133(52.4)$ & $180(74.4)$ & $x^{2}=6.195$ & 0.013 & $109(56.8)$ & $157(65.4)$ & $x^{2}=3.202$ & 0.074 \\
\hline Dizziness & $61(24.0)$ & $27(11.2)$ & -—— & -——- & $45(23.4)$ & $40(16.7)$ & - - - & - - - \\
\hline Vomiting & $19(7.5)$ & $11(4.6)$ & -—- & -——- & $7(3.6)$ & $25(10.4)$ & -—— & -—- \\
\hline Diarrhoea & $31(12.2)$ & $7(2.9)$ & -—- - & -——- & $27(14.1)$ & $12(5.0)$ & -二- & - - \\
\hline Headache) & $10(3.9)$ & $17(7.0)$ & -—-- & -—— & $4(2.1)$ & $6(2.5)$ & -—- & -—-— \\
\hline \multicolumn{9}{|c|}{ S. mansoni infection status (\%) } \\
\hline Positive & $97(14.1)$ & $142(22.0)$ & $x^{2}=2.165$ & 0.141 & $8(1.3)$ & $37(7.5)$ & $x^{2}=3.819$ & 0.051 \\
\hline Negative & $592(85.9)$ & $504(78.0)$ & -—-二 & -—- & $587(98.7)$ & $459(92.5)$ & -—- & -—— \\
\hline \multicolumn{9}{|c|}{ Intensity of S. mansoni infection (epg) } \\
\hline GMl epg & 78.4 & 322.5 & $t=2.412$ & 0.120 & 38.3 & 145.7 & $t=1.662$ & 0.197 \\
\hline
\end{tabular}

\section{Knowledge of schistosomiasis prevention}

The proportion of children with correct knowledge of schistosomiasis prevention in both the snack and nonsnack schools significantly reduced from $84.0 \%$ (95\% CI $80.5-87.1 \%)$ in 2013 to $62.1 \%$ (95 \% CI 56.3$67.5 \%)(p<0.001)$ in 2014 and from $86.4 \%(95 \%$ CI $83.4-89.0 \%)$ in 2013 to $56.0 \%$ (95 \% CI 50.8-61.3\%) $(p<0.001)$ in 2014, respectively. However, knowledge of schistosomiasis prevention in the snack and non-snack schools in 2014 was comparable; $62.1 \%$ (95 \% CI 57.7$66.4 \%)$ and $56.0 \%$ (95 \% CI 52.1-59.9\%) ( $p=0.412)$, respectively.

\section{Predictors of uptake of praziquantel}

Through a step wise backward elimination method, variables with $p<0.05$ from the unadjusted model (distance from school to the lake, sensitized about schistosomiasis, knowledge of schistosomiaisis prevention and eaten food prior to mass treatment) were considered for inclusion into the multivariable adjusted model. The only variable retained in the final model was eating food prior to mass treatment (adjusted risk ratio (ARR) 1.01, $95 \% \mathrm{CI}$ $1.01-1.02, p=0.020$ ) (Table 3).

\section{Discussion}

This study found that the 2014 uptake of praziquantel was lower than the 2013 uptake although the prevalence

Table 3 Estimated crude risk ratios (CRR) and adjusted risk ratio (ARR) and their $95 \% \mathrm{Cl}$ from the final logistic regression mixed-effects model for treatment uptake

\begin{tabular}{|c|c|c|c|c|}
\hline Variable & CRR $(95 \% \mathrm{Cl})$ & $p$-Value & ARR $(95 \% \mathrm{Cl})$ & $p$-Value \\
\hline \multicolumn{5}{|c|}{ Distance from school to the lake } \\
\hline$\leq 5 \mathrm{~km}$ & $1.13(1.03-1.24)$ & 0.009 & $1.00(0.99-1.00)$ & 0.343 \\
\hline \multicolumn{5}{|c|}{ Sensitized about schistosomiasis prevention } \\
\hline Yes & $1.38(1.18-1.61)$ & $<0.001$ & $1.01(0.01-1.03)$ & 0.247 \\
\hline
\end{tabular}

Correct knowledge of schistosomiasis prevention

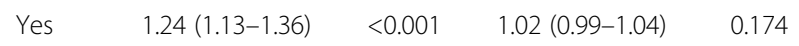

Eaten food prior to mass treatment

$$
1.01(1.00-1.02) \quad 0.020 \quad 1.01(1.00-1.02)
$$

Adjusted for age and sex 
and intensity of $S$. mansoni infection was unchanged between the years. The reported frequency of side-effects in 2014 was higher than that in 2013. Knowledge of schistosomiasis prevention was lower in 2014 than in 2013.

The observed decrease in uptake of treatment in 2014 may be attributable to lack of food for mitigating the side-effects of praziquantel. During the 2013 mass treatment, food to alleviate the side-effects and motivate the children to take treatment was provided to children with high levels of success [27]. The fear of side-effects as a major reason for non-uptake of praziquantel has been previously reported $[8,11,13]$. Food high in carbohydrate content increases the absorption of praziquantel form the gastro-intestinal tract, enhances its bioavailability and lowers the odds of side-effects [14-16]. During the 2014 mass treatment, only $54.4 \%$ compared to $92.8 \%$ of the children in the snack schools in 2013 reported to have taken food prior to mass treatment, the majority reporting maize porridge as the major type of food taken. The other types of food reported included pancakes, maize cobs and dry tea. This implies that a large proportion of children in 2014 took treatment on an empty stomach with the risk of widespread sideeffects. The drug distribution strategies in the non-snack schools in 2013 and 2014 were similar, with no specific measures to mitigate the side-effects and motivate children to take treatment on both occasions. This probably explains the unvarying uptake levels and occurrence of side-effects among children in this group. These data suggest that the reasons for the low uptake identified in our previous studies $[11,13,26]$ such as, inadequate information about schistosomiasis prevention, insufficient preparation and facilitation of teachers to distribute treatment and the fear of side-effects of praziquantel, especially when the drug is taken on an empty stomach are probably accurate and the measures suggested, such as provision of food in combination with education messages prior to treatment [27] are necessary to maintain high treatment coverage. A detailed cost-effectiveness analysis of provision of indigenous, locally available and relatively low cost food, such as maize porridge, during mass treatment should be undertaken and if found costeffective, provision of food should be integrated into school-based mass treatment. A multi-pronged strategy for provision of food by the national control program, parents or the Government could be used.

The prevalence and intensity of $S$. mansoni infection after mass treatment in 2013 and 2014 were unchanged in both groups of schools. Although the realized uptake in both the non-snack (70.4\%) and the snack schools (78.0 \%) during the 2014 mass treatment was lower than the 2013 uptake (78.7 and $93.9 \%$ ), the 2014 uptake was adequate to maintain the levels of infection but inadequate to significantly reduce the prevalence rates and intensity of the infection. In high transmission areas, chemotherapy with praziquantel is effective in reducing morbidity but the prevalence and intensity of infection return to pre-treatment levels within a short time if no other means of control are applied, even when treatment coverage is high [33]. In the study area, the majority of the children frequently visit the lake to fetch water, bathe, wash, fish and to swim $[10,11]$ and are thus at high risk of infection and reinfection. Sustained drop in infection can be achieved through a combination of interventions including preventive chemotherapy, health education, cessation of poor human sanitation practices and improved access to safe water [34, 35]. Each of these strategies is important but not sufficient when applied in isolation. Inadequate resources and capacity for such measures are major obstacles to sustainable schistosomiasis control in developing countries [36]. In the study area, school-based mass treatment with praziquantel is the mainstay for schistosomiasis control among school-age children. The challenges associated with this strategy have been discussed elsewhere [6, 7, 37, 38].

Knowledge of schistosomiasis prevention in both groups of schools in 2014 was considerably lower than that in 2013, a manifestation of the insufficient health education provided in 2014. Prior to the 2013 mass treatment, education messages tailored to the knowledge gap in schistosomiasis prevention were provided to all children in both groups of schools with high levels of knowledge registered in the schools. In 2014, less than a half of the children in both the snack and non-snack schools reported to have been sensitized about schistosomiasis prior to mass treatment. As such, a significant reduction in the proportion of children with adequate knowledge of schistosomiasis prevention was noted in both groups of schools. Health education and other behavioural change interventions are effective strategies for increasing compliance to treatment for schistosomiasis [39-41]. In the absence of these interventions, there is a risk that the targeted populations may resist treatment $[9,39]$.

\section{Study limitations}

Children who participated in both studies were selected at random. It is possible that some of the children examined in 2013 could have been re-examined in 2014 and provided similar responses on both occasions. However, the correlation between self-reported uptake and $S$. mansoni infection and intensity validated the selfreported uptake as accurate. A negative linear relationship between uptake of praziquantel and prevalence as well as intensity of $S$. mansoni infection was observed: In schools with high uptake, the prevalence and intensity 
of S. mansoni infection was much lower than in schools with low uptake. Secondly, the Kato-Katz technique adopted for this study analyses a small amount of stool $(41.7 \mathrm{mg})$ and therefore has a relatively low capacity to detect eggs from specimens of low intensity infections $[30,42]$. The sensitivity of the method was increased by examining two stool samples from each child and preparing two thick stool smears from each sample.

\section{Conclusions}

This study shows that in the absence of food to motivate children to take treatment and to mitigate the side-effects of praziquantel, uptake of praziquantel reduces and the side-effects of the drug increase. Thus, strategies for maintaining high treatment coverage are needed. Such strategies should include continued sensitization and education of the children and provision of food at school to mitigate the side-effects attributable to praziquantel treatment and motivate children to take treatment.

\section{Competing interests}

The authors declare that they have no competing interests.

\section{Authors' contributions}

SM, FN, AK and AO participated in the design of the study. SM participated in data collection, performed the statistical analysis and drafted the article. All authors reviewed the manuscript. All authors read and approved the final manuscript.

\section{Acknowledgements}

The authors are grateful to all the research assistants and laboratory personnel who participated in data collection. We acknowledge the cooperation of the school management and the teachers who are responsible for distributing treatment. The authors are indebted to the staff of Ministry of Health, Vector Control Division, Uganda for their support in the laboratory work of the study and to the Danish Ministry of Foreign Affairs for funding the study.

\section{Author details}

${ }^{1}$ School of Medicine, Child Health and Development Center, Makerere University, Kampala, Uganda. ${ }^{2}$ Faculty of Health and Medical Sciences, Section for Parasitology and Aquatic Diseases, University of Copenhagen, Copenhagen, Denmark. ${ }^{3}$ School of Public Health, Makerere University, Kampala, Uganda.

Received: 26 May 2015 Accepted: 30 September 2015

Published online: 14 October 2015

\section{References}

1. Kabatereine NB, Brooker S, Tukahebwa EM, Kazibwe F, Onapa AW. Epidemiology and geography of Schistosomiaisis mansoni in Uganda: implications for planning control. Trop Med Int Health. 2004;9:372-80.

2. Brooker S, Kabatereine NB, Fleming F, Devlin N. Cost and cost-effectiveness of nationwide school-based helminth control in Uganda: intra-country variation and effects of scaling-up. Health Policy Plan. 2008;23(1):24-35.

3. Brooker S, Marriot H, Hall A, Adjei S, Allan E, Maier C, et al. Community perception of school-based delivery of anthelmintics in Ghana and Tanzania. Trop Med Int Health. 2001;6(12):1075-83.

4. Bundy DA, Guyatt HL. Schools for health: Focus on health, education and the school-age child. Parasitol Today. 1996;12(8):suppl 1-16.

5. Magnussen P, Ndawi B, Sheshe AK, Byskov J, Mbwana K, Christensen NO. The impact of a school health programme on the prevalence and morbidity of urinary schistosomiasis in Mwera Division, Pangani District, Tanzania. Trans R Soc Trop Med Hyg. 2001;95(1):58-64
6. Allen T, Parker M. Will increased funding for neglected tropical diseases really make poverty history? Lancet. 2012;379(9821):1097-8. author reply 1098-1100.

7. Mafe MA, Appelt B, Adewale B, Idowu ET, Akinwale OP, Adeneye AK, et al. Effectiveness of different approaches to mass delivery of praziquantel among school-aged children in rural communities in Nigeria. Acta Trop. 2005;93(2):181-90

8. Parker M, Allen T. Does mass drug administration for the integrated treatment of neglected tropical diseases really work? Assessing evidence for the control of schistosomiasis and soil-transmitted helminths in Uganda. Health Res Policy Syst. 2011;9:3.

9. Parker M, Allen T, Hastings J. Resisting control of neglected tropical diseases: dilemmas in the mass treatment of schistosomiasis and soil-transmitted helminths in north-west Uganda. J Biosoc Sci. 2008;40(2):161-81.

10. Muhumuza S, Kitimbo G, Oryema-Lalobo M, Nuwaha F. Association between socio economic status and schistosomiasis infection in Jinja District. Uganda Trop Med Int Health. 2009;14(6):612-9.

11. Muhumuza S, Olsen A, Katahoire A, Nuwaha F. Uptake of preventive treatment for intestinal schistosomiasis among school children in jinja district, Uganda: A cross sectional study. PLoS One. 2013;8(5):e63438.

12. WHO. Prevention and control of schistosomiasis and soil-transmitted helminthiasis: report of a WHO expert committee. Geneva: WHO Tech Rep Ser; 2002.

13. Muhumuza S, Katahoire A, Nuwaha F, Olsen A. Increasing teacher motivation and supervision is an important but not sufficient strategy for improving praziquantel uptake in Schistosoma mansoni control programs: serial cross sectional surveys in Uganda. BMC Infect Dis. 2013;13:590.

14. Castro N, Medina R, Sotelo J, Jung H. Bioavailability of praziquantel increases with concomitant administration of food. Antimicrob Agents Chemother. 2000;44(10):2903-4.

15. Mandour ME, el Turabi H, Homeida MM, el Sadig T, Ali HM, Bennett JL, et al. Pharmacokinetics of praziquantel in healthy volunteers and patients with schistosomiasis. Trans R Soc Trop Med Hyg. 1990;84(3):389-93.

16. Njomo D, Tomono N, Muhoho N, Mitsui Y, Josyline K, Mwandawiro C The adverse effects of albendazole and praziquantel in mass drug administration by trained school teachers. Afr J Health Sci. 2010;17:10-4.

17. Govindasamy D, Meghij J, Kebede Negussi E, Clare Baggaley R, Ford N, Kranzer K. Interventions to improve or facilitate linkage to or retention in pre-ART (HIV) care and initiation of ART in low- and middle-income settings-a systematic review. J Int AIDS Soc. 2014;17(1):19032.

18. Hodges MH, Dada N, Warmsley A, Paye J, Bangura MM, Nyorkor E, et al. Mass drug administration significantly reduces infection of Schistosoma mansoni and hookworm in school children in the national control program in Sierra Leone. BMC Infect Dis. 2012;12:16.

19. Kundu CK, Samanta M, Sarkar M, Bhattacharyya S, Chatterjee S. Food supplementation as an incentive to improve pre-antiretroviral therapy clinic adherence in HIV-positive children-experience from eastern India. J Trop Pediatr. 2012;58(1):31-7.

20. Acham H, Kikafunda JK, Malde MK, Oldewage-Theron WH, Egal AA Breakfast, midday meals and academic achievement in rural primary schools in Uganda: implications for education and school health policy. Food Nutr Res. 2012:56

21. Pollitt $E_{1}$ Gersovitz M, Gargiulo M. Educational benefits of the United States school feeding program: a critical review of the literature. Am J Public Health. 1978:68(5):477-81

22. G.O.U. The Education (pre-primary, primary and post-primary) Act, 2008, (Act 13 supplement). In.; 2008.

23. GCNF. School Feeding in Uganda, 2006. Report for the Global Child Nutrition Forum. http://www.genf.org/library/country-reports/uganda/ 2006-Uganda-School-Feeding.pdf [cited 25 August 2011]. In.; 2006.

24. Kabatereine NB, Kemijumbi J, Ouma JH, Sturrock RF, Butterworth AE, Madsen $\mathrm{H}$, et al. Efficacy and side effects of praziquantel treatment in a highly endemic Schistosoma mansoni focus at Lake Albert, Uganda. Trans R Soc Trop Med Hyg. 2003;97(5):599-603.

25. Ndyomugyenyi R, Kabatereine NB. Integrated community-directed treatment for the control of onchocerciasis, schistosomiasis and intestinal helminths infections in Uganda: advantages and disadvantages. Trop Med Int Health. 2003;8(11):997-1004.

26. Muhumuza S, Olsen A, Nuwaha F, Katahoire A Understanding Low Uptake of Mass Treatment for Intestinal Schistosomiasis among School Children: A Qualitative Study in Jinja District, Uganda. J Biosoc Sci 2014:1-16. 
27. Muhumuza S, Olsen A, Katahoire A, Kiragga AN, Nuwaha F. Effectiveness of a pre-treatment snack on the uptake of mass treatment for schistosomiasis in Uganda: a cluster randomized trial. PLoS Med. 2014;11(5):e1001640.

28. Katz N, Chaves A, Pellegrino J. A simple device for quantitative stool thick-smear technique in Schistosomiasis mansoni. Rev Inst Med Trop Sao Paulo. 1972;14(6):397-400

29. Glinz D, Silue KD, Knopp S, Lohourignon LK, Yao KP, Steinmann P, et al. Comparing diagnostic accuracy of Kato-Katz, Koga agar plate, etherconcentration, and FLOTAC for Schistosoma mansoni and soil-transmitted helminths. PLoS Negl Trop Dis. 2010;4(7):e754.

30. Lin DD, Liu JX, Liu YM, Hu F, Zhang YY, Xu JM, et al. Routine Kato-KatZ technique underestimates the prevalence of Schistosoma japonicum: a case study in an endemic area of the People's Republic of China. Parasitol Int. 2008;57(3):281-6

31. Campbell M, Grimshaw J, Steen N. Sample size calculations for cluster randomised trials. Changing Professional Practice in Europe Group (EU BIOMED II Concerted Action). J Health Serv Res Policy. 2000:5(1):12-6.

32. Donner A. Some aspects of the design and analysis of cluster randomized trials. Appl Stat. 1998:47:95-113.

33. N'Goran EK, Utzinger J, N'Guessan AN, Muller I, Zamble K, Lohourignon KL, et al. Reinfection with Schistosoma haematobium following school-based chemotherapy with praziquantel in four highly endemic villages in Cote d'Ivoire. Trop Med Int Health. 2001;6(10):817-25.

34. Freeman MC, Ogden S, Jacobson J, Abbott D, Addiss DG, Amnie AG, et al. Integration of water, sanitation, and hygiene for the prevention and control of neglected tropical diseases: a rationale for inter-sectoral collaboration. PLoS Negl Trop Dis. 2013;7(9):e2439.

35. Knopp S, Becker SL, Ingram KJ, Keiser J, Utzinger J. Diagnosis and treatment of schistosomiasis in children in the era of intensified control. Expert Rev Anti-Infect Ther. 2013;11(11):1237-58.

36. WHO. Accelerating work to overcome the global impact of neglected tropical diseases - a road for implementation. Geneva: World health organization; 2012.

37. Allen T, Parker M. The "other diseases" of the Millennium Development Goals: rhetoric and reality of free drug distribution to cure the poor's parasites. Third World Q. 2011;32(1):91-117.

38. Why Don't People Take their Medicine? Experimental Evidence from Kenya: http://www.researcgate.net/publication/228602508.

39. Lansdown R, Ledward A, Hall A, Issae W, Yona E, Matulu J, et al. Schistosomiasis, helminth infection and health education in Tanzania: achieving behaviour change in primary schools. Health Educ Res. 2002;17(4):425-33.

40. Schall V, Diniz MCP. Information and education in schistosomiasis control: an analysis of the situation in the state of Minas Gerais, Brazil. Mem Inst Oswaldo Cruz. 2001;96:35-43

41. Yuan LP, Manderson L, Ren MY, Li GP, Yu DB, Fang JC. School-based interventions to enhance knowledge and improve case management of schistosomiasis: a case study from Hunan, China. Acta Trop. 2005:96(2):248-54.

42. de Vlas SJ, Gryseels B. Underestimation of Schistosoma mansoni prevalences. Parasitol Today. 1992:8(8):274-7.

\section{Submit your next manuscript to BioMed Central and take full advantage of:}

- Convenient online submission

- Thorough peer review

- No space constraints or color figure charges

- Immediate publication on acceptance

- Inclusion in PubMed, CAS, Scopus and Google Scholar

- Research which is freely available for redistribution

Submit your manuscript at www.biomedcentral.com/submit 